\title{
Single phase (cyclohexane-assisted) transesterification of Jatropha curcas seed oil using full factorial design of experiment
}

\author{
Ibrahim Ali Mohammed-Dabo ${ }^{1,}$, , Muhammad Sada Ahmad ${ }^{2}$ \\ ${ }^{1}$ Chemical Engineering Department, Ahmadu Bello University Zaria, Kaduna State Nigeria \\ ${ }^{2}$ Center for Renewable Energy Research, Umaru Musa Yar'adua University, Katsina State Nigeria
}

Email address:

iroali@mail.ru(I. A. Mohammed-Dabo)

To cite this article:

Ibrahim Ali Mohammed-Dabo, Muhammad Sada Ahmad. Single phase (Cyclohexane-Assisted) Transesterification of Jatropha Curcas Seed Oil Using Full Factorial Design of Experiment. International Journal of Renewable and Sustainable Energy.

Vol. 2, No. 5, 2013, pp. 191-197. doi: 10.11648/j.ijrse.20130205.11

\begin{abstract}
This work was aimed at reduction of time, energy and material consumption of transesterification reaction by introduction of cosolvent to overcome this mass transfer resistance. The oil was characterized and its properties were found to conform to those of the literature. The GC-MS analysis of the raw oil indicates that the major fatty acids were; palmitic acid (15.86\%), Oleic acid (37.13\%), linoleic acid (37.24\%) and stearic acid $(9.76 \%)$, this indicates that the major fatty acids are unsaturated acids. The work uses full factorial design of experiment to investigate the main and interaction effects of five factors (varied at two levels of high and low) affecting transesterification. Methanol/oil molar ratio (41.49\%) was found to be the most significant effect followed by catalyst concentration (30.54\%), temperature (8.05\%), and time (1.45\%). For the interaction effects, the interaction of methanol/oil molar ratio with catalyst concentration $(1.52 \%)$ was found to be most significant interaction this was then followed by the interaction of temperature and methanol/oil molar ratio (1.30\%). However, the effect of methanol/cosolvent volume ratio was found to be insignificant. The model equations developed were subjected to some constrains and an optimum yield of $69.40 \%$ was obtained at 3.85 minutes, $60^{\circ} \mathrm{C}, 0.5 \%$ catalyst concentration, 6:1 methanol/oil molar ratio and 1:1 methanol/cosolvent volume ratio. The GC-MS analysis of samples produced at various conditions with least time confirms the formation of fatty acid methyl ester and the properties of the biodiesel produced at the optimum conditions were found to conform to ASTM D6751-02 B100.
\end{abstract}

Keyword: Transesterification, Biodiesel, Cosolvent, Full Factorial Design, Cyclohexane, FAME

\section{Introduction}

Biodiesel is a mono alkyl-ester diesel-equivalent biofuel, made from transesterification reaction of renewable biological materials such as vegetable oils or animal fats with methanol [1]. It has low volatility, high pour and cloud points, and reduces sulphur dioxide emission $[2,3]$. It produces less smoke and particulate, low carbon monoxide and hydrocarbon emission and in addition it has high cetane number and is biodegradable [4].

Transesterification is the chemical reaction between triglycerides and alcohol in the presence of catalyst to produce mono-esters. It consists of a sequence of three consecutive reversible reactions. That is, conversion of triglycerides to diglycerides, followed by the conversion of diglycerides to monoglycerides. The glycerides are converted into glycerol and yielding one ester molecule in each step having similar properties with diesel [5]. The major problem associated with conventional transesterification reaction is the immiscibility of oil and alcohol because of the difference in polarity resulting in mass transfer resistance. This lowers the rate of collisions of molecules and so the rate of reaction causing longer reaction times, high material and energy consumption and consequently higher operating expenses, higher labour, higher fixed capital investments and consequently higher product cost [6].

This paper seeks to overcome the mass transfer resistance associated with conventional transesterification using a cosolvent (cyclohexane) as a phase transfer catalyst (PTC). The work uses full factorial design of experiment (DOE) to find both the main and interaction effects of five factors (time, temperature, catalyst concentration, methanol 
to oil molar ratio \& methanol to cosolvent volume ratio) in a matrix of 32 experiments conducted in a randomized order to overcome the lurking effects of those factors that changes with time. These main and interaction effects were tested for statistical significance by using appropriate factorial ANOVA (Analysis of Variance) test using Design Expert 6.0 software. The major assumptions for factorial ANOVA are the independence of observation and the homogeneity of variance [7]. The resulting statistical model equation (Equation $2 \& 3$ ) developed for the yield as a function of these five factors were then subjected to some constrains to determine the optimum conditions. The biodiesel produced at these optimum conditions was then analyzed using GC-MS to confirm the formation of fatty acid methyl ester (FAME). Finally, the properties of the FAME produced at the optimum conditions were tested using standard testing method and compared with ASTM

\section{D6751-02 B100.}

\section{Design of Experiment}

The hypothesis is that the yield of biodiesel is not a function of Time (A), Temperature (B), Catalyst concentration (C), Methanol to oil molar ratio (D) and Methanol to cosolvent volume ratio. This is depicted in equation 1 below. The stirring speed was fixed at $100 \mathrm{rpm}$ (Caglar, 2007). The factors were varied at high and low values (Table 1) and base on this, a matrix of 32 experiments $\left(2^{n}=2^{5}=32\right.$; where $n=$ number of factors $)$ were designed in a randomized order using design matrix builder of DESIGN EXPERT 6.0. Table 5 gives this design layout.

$$
Y \neq f\left(\mathrm{~A}_{2} \mathrm{~B}, \mathrm{C}, \mathrm{D}, \mathrm{E}\right)
$$

Table 1: Low and High Values of factors

\begin{tabular}{|c|c|c|c|c|c|c|c|}
\hline Factor & Name & Units & Type & $\begin{array}{l}\text { Low } \\
\text { Actual }\end{array}$ & High Actual & $\begin{array}{l}\text { Low } \\
\text { Coded }\end{array}$ & $\begin{array}{l}\text { High } \\
\text { Coded }\end{array}$ \\
\hline A & TIME & Minute & Numeric & 1 & 10 & -1 & 1 \\
\hline B & TEMPERATURE & $\operatorname{deg} \mathrm{C}$ & Numeric & 30 & 60 & -1 & 1 \\
\hline $\mathrm{C}$ & CATALYST CONCENTRATION & $\%$ & Numeric & 0.5 & 2 & -1 & 1 \\
\hline $\mathrm{D}$ & METHANOL/OIL & $\begin{array}{l}\text { molar } \\
\text { ratio }\end{array}$ & Numeric & 3 & 6 & -1 & 1 \\
\hline $\mathrm{F}$ & METHANOL/COSOLVENT & $\begin{array}{l}\text { volume } \\
\text { ratio }\end{array}$ & Numeric & 1 & 3 & -1 & 1 \\
\hline
\end{tabular}

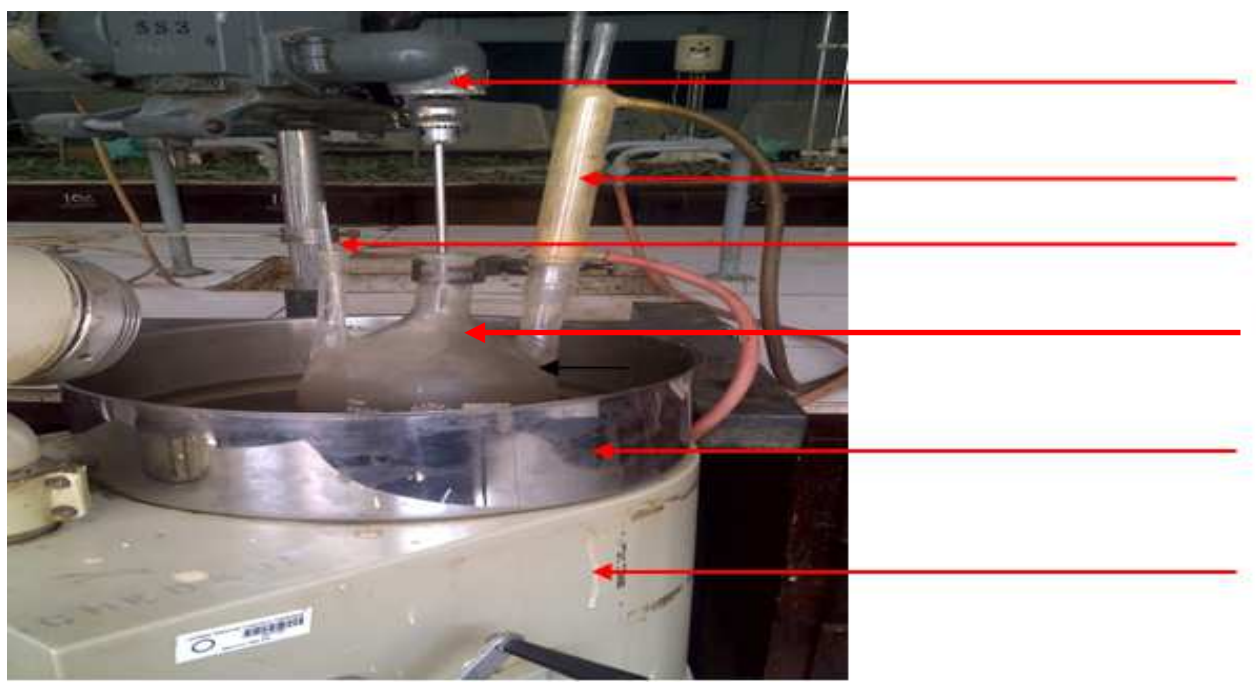

Stirrer

Condenser

Thermometer

3-Necked flask

Bath

Heat Source

Figure 1. Esterification/Transeterification experimental set up

\section{Materials and Methods}

\subsection{Materials}

Jatropha Curcas seed was obtained from oil seed research unit of the Institute for Agricultural Research (IAR), Ahmadu Bello University Zaria, cyclohexane, anhydrous methanol, sodium hydroxide, potassium hydroxide, isopropyl alcohol, ethanol, cyclohexene, tetraoxosulphate (IV) acid, hydrochloric acid, carbon tetrachloride, potassium iodide, potassium dichromate and wijs solution were procured from SteveMore Chemical Company, Zaria and were of analytical grade.

\subsection{Methodology}

\subsubsection{Oil Characterization and Esterification}

The Jatropha Curcas seed oil was extracted mechanically from the seed, characterized for fatty acid composition (using GC-MS analysis), and then for its physical and 
chemical properties based on ASTM and AOCS Standard Methods. The oil was then heated to a temperature of $130^{\circ}$ $\mathrm{C}$ to vaporize moisture and allowed to settle over night. It was then decanted and filtered to remove any suspended solid particles. The oil, having high FFA content was then esterified with $20 \% \mathrm{w} / \mathrm{w}$ methanol, using $5 \% \mathrm{w} / \mathrm{w}$ tetraoxosulphate (VI) of the oil in a three neck round bottom flask equipped with condenser and a suspended mechanical stirrer at 100rpm (Figure 1). The process was conducted at $60^{\circ} \mathrm{C}$ for 5 hours to reduce the free fatty acid composition. The unreacted methanol was then separated from the esterified oil using a separating funnel [8].

\subsubsection{Oil Transesterification}

Batches of $50 \mathrm{~g}$ of the esterified oil were then transesterifed in the same set-up (Figure 1) as that of the esterification in accordance with the experimental design layout of Table 1. In each case upon completion of the reaction, the mixture was neutralized by addition of 1 drop of $0.6 \mathrm{~N} \mathrm{H}_{2} \mathrm{SO}_{4}$, cooled in an ice bath and poured into a separating funnel to separate the fatty acid methyl ester (FAME) from the glycerol by gravity [9]. The glycerol settled at the bottom and was removed while the methyl ester was washed with hot distilled water and the yield calculated in each case. The produced biodiesel samples were characterized employing appropriate standard procedures presented in [10].

\section{Results and Discussion}

\subsection{Fatty Acid Composition of Oil}

Table 2 depicts the fatty acid composition of the crude Jatropha Curcas seed oil used in this work and is comparable to those reported by Makkar et al., 1997 [11]. The GC-MS result indicates that the oil contained more unsaturated fatty acid (linoleic acid (37.24\%) and oleic acid $(37.13 \%)$ than the saturated acids (palmitic (15.86\%) acid and stearic acid (9.76\%). This accounts for the higher iodine value of the oil (100.56 $\mathrm{g}$ of Iodine $/ 100 \mathrm{~g}$ of oil sample). The presence of high amount of unsaturates also further confirms why Jatropha seed oil does not congeal at room temperature making it a good candidate for biodiesel production [12]. The remaining percentage of fatty acid that goes undetected is probably due to impurities contained in the oil.

Table 2: Fatty acid composition of Jatropha curcas seed oil used

\begin{tabular}{llll}
\hline S/no & Component & Std Comp (wt \%) & $\begin{array}{l}\text { Measured Comp } \\
\text { (\%) wt }\end{array}$ \\
\hline 1 & Palmitic acid (16:0) & 15.86 & 18.22 \\
2 & Linoleic acid (18:2) & 37.24 & 48.18 \\
3 & Oleic acid (18:1) & 37.13 & 28.46 \\
4 & Stearic acid (18:0) & 9.76 & 5.14 \\
5. & MW $_{\text {aveg. }}(\mathrm{g} / \mathrm{mol})$ & 894 & 874 \\
\hline
\end{tabular}

\subsection{Properties of Raw Oil}

Properties of the raw jatropha oil (Table 3) analyzed included; Saponification value (202.34 mgKOH/g oil), Iodine Value $(100.56 \mathrm{~g}$ of iodine $/ 100 \mathrm{~g}$ of oil), Cetane Number (50.6484), Density $\left(874 \mathrm{Kg} / \mathrm{m}^{3}\right)$, Viscosity $\left(38.43 \mathrm{~mm}^{2} / \mathrm{s} @ 25^{\circ} \mathrm{C}\right)$ and moisture content $(0.4 \%)$. The calorific value of the raw Jatropha curcas seed oil was found to be $37.23 \mathrm{MJ} / \mathrm{Kg}$. However, the free fatty acid content of the raw jatropha oil was $14.8 \%$ which is not within the specified limit for biodiesel production $(<1 \%)$. Therefore, the raw jatropha oil needed to be neutralized via esterification reaction with methanol and tetraoxosulphate (IV) acid as catalyst [5].

Table 3: Properties of raw Jatropha oil used

\begin{tabular}{llll}
\hline S/No & Property & Unit & Value \\
\hline 1 & FFA & $\%$ & 14.8 \\
2 & Sap value & $\mathrm{mg} \mathrm{KOH} / \mathrm{g}$ oil & 202.34 \\
3 & Iodine value & $\mathrm{g}$ of Iodine/100g of sample & 100.56 \\
4 & Cetane number & & 50.6484 \\
5 & Density & $\mathrm{Kg} / \mathrm{m}^{3}$ & 874 \\
6 & Calorific value & $\mathrm{MJ} / \mathrm{Kg}$ & 34.9034 \\
7 & Viscosity $@ 25 \mathrm{C}$ & $\mathrm{mm} / \mathrm{s}$ & 38.43 \\
9 & Acid value & $\%$ & 29.6 \\
10 & Moisture content & $\%$ & 0.4 \\
\hline
\end{tabular}

\subsection{Statistical Analysis}

Table 5 presents the complete experimental design layout of this research work. From the table, it can be observed that, the biodiesel yield ranges from 23.07 to $78.34 \%$. The ratio of the maximum to minimum yield is 3.40 which is lower than 10 hence transformation was not needed because a ratio greater than 10 usually indicates the need for transformation. The most Significant effects were picked from left to right of the half normal plot until the line matches up with the majority of the effects near zero. Table 4 gives the contribution of these picked effects to the model. For the main effect, methanol/oil molar ratio, D, was found to be the most significant $(41.49 \%)$ then catalyst concentration, $\mathrm{C},(30.54 \%)$ which was then followed by temperature, $\mathrm{B},(8.05 \%)$ and time, $\mathrm{A},(1.45 \%)$. For the interaction effects, the combined effect of methanol/oil molar ratio with catalyst concentration was found to be higher $(1.52 \%)$ followed by temperature/methanol/oil molar ratio $(1.30 \%)$. However, methanol/cosolvent volume ratio, F, was found to be insignificant in the process. Equations 1 and 2 present the model equations in terms of codes and actual factors respectively.

Model equation in terms of coded factors: 


$$
\mathrm{Y}=49.5+2.81 \mathrm{~A}+5.04 \mathrm{~B}-9.80 \mathrm{C}+11.4 \mathrm{D}-4.71 \mathrm{~F}+2.02 \mathrm{BD}-2.18 \mathrm{CD}
$$

Model equation in terms of actual factor:

$$
\mathrm{Y}=18.9+0.401 \mathrm{~A}-0.0680 \mathrm{~B}-1.59 \mathrm{C}+4.55 \mathrm{D}+0.0898 \mathrm{BD}-1.94 \mathrm{CD}
$$

Table 4: Effects contribution in the model

\begin{tabular}{llll}
\hline Model Term & Effect & Sum of Square & \% Contribution \\
\hline A & 5.62 & 291.11 & 1.45 \\
B & 10.11 & 1615.59 & 8.05 \\
C & -19.63 & 6128.12 & 30.54 \\
D & 22.86 & 8327.08 & 41.49 \\
BD & 4.05 & 261.70 & 1.30 \\
CD & -4.37 & 305.86 & 1.52 \\
\hline
\end{tabular}

\begin{tabular}{|c|c|c|c|c|c|c|}
\hline Run & $\begin{array}{l}\text { Time } \\
(\mathrm{min})\end{array}$ & $\begin{array}{l}\text { Temp., } \\
{ }^{0} \mathrm{C} \\
\end{array}$ & $\begin{array}{l}\text { Cat. conc. } \\
(\%)\end{array}$ & $\begin{array}{l}\text { Methanol/oil } \\
\text { (molar ratio) }\end{array}$ & $\begin{array}{l}\text { Methanol/cosolvent } \\
\text { (volume ratio) }\end{array}$ & $\begin{array}{l}\text { Yield } \\
(\%)\end{array}$ \\
\hline 1 & 1 & 60 & 2 & 3 & 3 & 30.36 \\
\hline 2 & 1 & 30 & 0.5 & 6 & 3 & 50.61 \\
\hline 3 & 15 & 30 & 2 & 6 & 3 & 41.67 \\
\hline 4 & 1 & 30 & 2 & 6 & 3 & 35.42 \\
\hline 5 & 1 & 60 & 0.5 & 6 & 3 & 63.26 \\
\hline 6 & 15 & 60 & 2 & 6 & 3 & 52.09 \\
\hline 7 & 1 & 30 & 2 & 3 & 1 & 23.07 \\
\hline 8 & 1 & 30 & 2 & 3 & 3 & 24.29 \\
\hline 9 & 15 & 30 & 2 & 6 & 1 & 43.87 \\
\hline 10 & 1 & 60 & 2 & 6 & 3 & 44.28 \\
\hline 11 & 1 & 30 & 0.5 & 6 & 1 & 53.27 \\
\hline 12 & 15 & 60 & 0.5 & 3 & 1 & 47 \\
\hline 13 & 1 & 30 & 2 & 6 & 1 & 37.29 \\
\hline 14 & 1 & 30 & 0.5 & 3 & 3 & 34.7 \\
\hline 15 & 1 & 60 & 2 & 6 & 1 & 46.61 \\
\hline 16 & 1 & 60 & 2 & 3 & 1 & 27 \\
\hline 17 & 15 & 60 & 0.5 & 3 & 3 & 51.03 \\
\hline 18 & 1 & 60 & 0.5 & 3 & 1 & 39.95 \\
\hline 19 & 15 & 60 & 2 & 3 & 1 & 37.6 \\
\hline 20 & 15 & 30 & 2 & 3 & 3 & 28.58 \\
\hline 21 & 15 & 30 & 0.5 & 3 & 1 & 42.97 \\
\hline 22 & 1 & 60 & 0.5 & 3 & 3 & 43.37 \\
\hline 23 & 15 & 30 & 0.5 & 6 & 3 & 59.54 \\
\hline 24 & 15 & 60 & 2 & 3 & 3 & 35.72 \\
\hline 25 & 15 & 60 & 0.5 & 6 & 3 & 74.42 \\
\hline 26 & 15 & 60 & 0.5 & 6 & 1 & 78.34 \\
\hline 27 & 1 & 30 & 0.5 & 3 & 1 & 31.96 \\
\hline 28 & 15 & 30 & 0.5 & 3 & 3 & 40.82 \\
\hline 29 & 15 & 60 & 2 & 6 & 1 & 54.83 \\
\hline 30 & 15 & 30 & 0.5 & 6 & 1 & 62.59 \\
\hline 31 & 1 & 60 & 0.5 & 6 & 1 & 66.59 \\
\hline 32 & 15 & 30 & 2 & 3 & 1 & 30.08 \\
\hline
\end{tabular}

Table 5: Experimental design layout 


\subsection{Main Effect}

\subsubsection{Time (A)}

Time is the only factor that was not involved in interaction among the four significant factors selected out of the five under consideration. Interpreting the factors involved in interaction provides misleading information, therefore only time will be considered in the discussion of the main effect. From Figure 1 it can be seen that, the yield of biodiesel during transesterification is directly proportional to the reaction time, increase in time of reaction resulted into an increase in the biodiesel yield. This is because of increase in mixing and dispersion of methanol in oil phase with increase in reaction time [13]. However, increase in time beyond the optimum does not increase the yield but favors the backward reaction (hydrolysis of ester) which results in reduction of product yield [10]. In the course of optimization, 17 solutions were found at varying time ranging from 1-15 minutes with yield increasing with increase in time. However, one minute is the recommended design point since it will make it easier to design continues reactor to operate at 1 minute than at any other time above one minute.

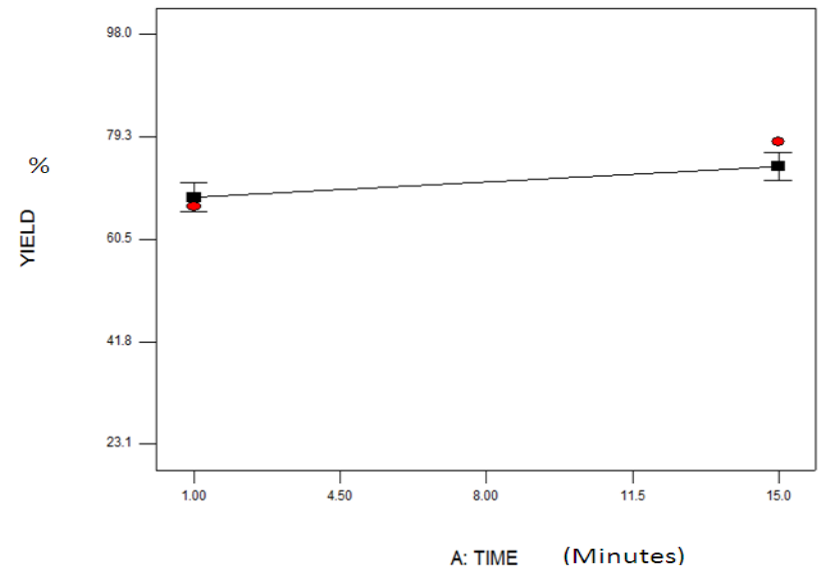

Figure 1: Effect of time on yield of FAME

\subsection{Interaction Effects}

\subsubsection{Methanol/Oil Molar Ratio and Temperature Interaction}

Methanol/oil molar ratio and temperature interactions, the I-Beam symbol on the plots (Fig 2) depict the 95\% least significant difference interval for the plotted points. Since the points have no overlapping intervals then they are significantly different. However, the spread of the points on the right hand side (temperature is high) of the graph is wider than the spread between the points on the left hand side (temperature is low) of the graph. In other words, the effect of methanol/oil molar ratio is more significant at high temperature, therefore increasing the temperature will lower the concentration of methanol required to achieve higher yield [14]. This is probably because for most organic reactions increase in temperature leads to increase in rate of reaction. Although increase in temperature favors the reaction, an optimum temperature of $60^{\circ} \mathrm{C}$ was chosen in order to avoid higher temperature which will bring about methanol vaporization [15]. At that temperature an optimum methanol to oil molar ratio of $6: 1$ was observed.

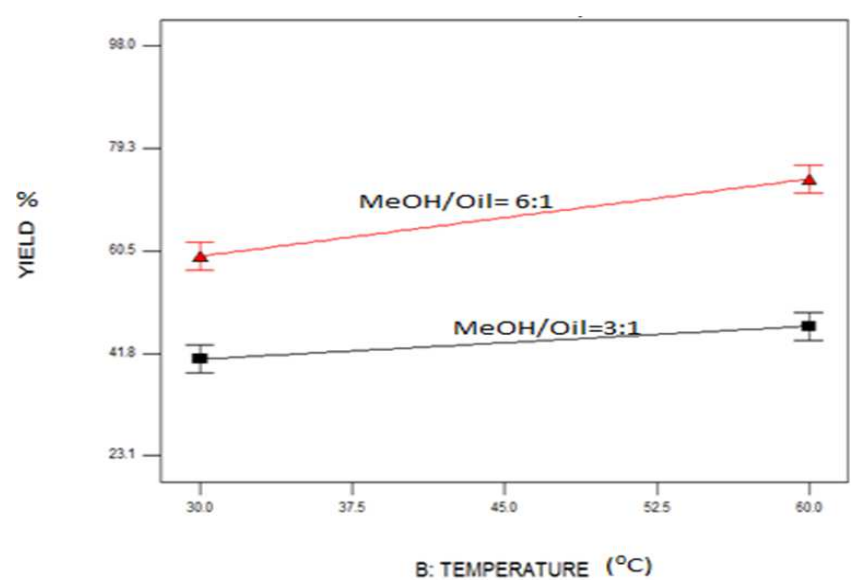

Figure 2: Interaction of Methanol/oil molar ratio and temperature

\subsubsection{Methanol/Oil Molar Ratio and Catalyst Concentration Interaction}

Fig 3 gives methanol/oil molar ratio/catalyst concentration interactions. the points have no overlapping intervals then they are significantly different. However, the spread of the points on the left hand side (low catalyst concentration) of the graph is wider than the spread between the points on the right hand side (high catalyst concentration) of the graph. In other words, the effect of methanol/oil molar ratio is more significant at low catalyst concentration therefore decreasing the catalyst concentration will lower the concentration of methanol required to achieve higher yields this is because high catalyst concentration facilitates saponification and consequently decreases yield [1]. An optimum methanol/oil molar ratio of $6: 1$ has been observed for this work at $0.5 \% \mathrm{w} / \mathrm{w}$ catalyst concentration. This is consistent with the results obtain by [6]

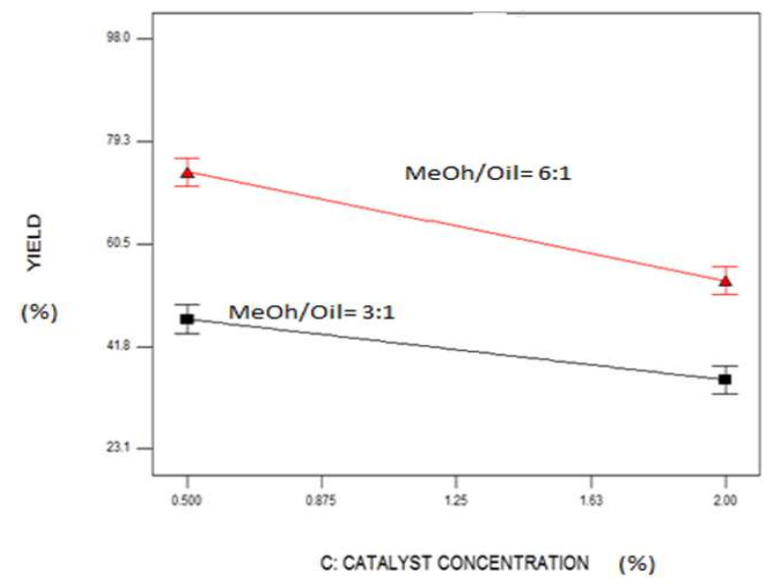

Figure 3: Interaction of Methanol/oil molar ratio and catalyst concentration 


\subsection{Optimization}

The optimization was performed for the purpose of maximizing the biodiesel yield. The targeted yield here is 98\%. The system was subjected to the following constrains: Time (in range of 1-10 minutes), Temperature (in range 30$60^{\circ}$ ), catalyst concentration (in range $0.5-2 \%$ ), and methanol/oil molar ratio (in range 3:1-6:1). But since methanol/cosolvent volume ratio was found to be insignificant it was fixed at 1:1. The number of cycles per optimization was kept at 30 and duplicate solution filter kept on the positive, 17 solutions were found which were all ranked on the basis of desirability. Three of the solutions with the lowest time of reaction (shown in Table 6) were selected and analysed by GC-MS. Their GC-MS analysis confirmed the formation of FAME.

Table 6: Optimized results with lowest time

\begin{tabular}{llllll}
\hline $\begin{array}{l}\text { TIME } \\
(\text { Min) }\end{array}$ & $\begin{array}{l}\text { TEMP } \\
{ }^{\mathbf{0}} \mathbf{C}\end{array}$ & CATALYST CONC (\%) & $\begin{array}{l}\text { MEOH/OIL } \\
(\text { Molar ratio) }\end{array}$ & $\begin{array}{l}\text { MeOH/COSOLVENT } \\
\text { (Vol. Ratio) }\end{array}$ & $\begin{array}{l}\text { YIELD } \\
(\%)\end{array}$ \\
\hline 1 & 45 & 0.5 & $06: 01$ & $01: 01$ & 61.3 \\
2.19 & 60 & 0.5 & $06: 01$ & $01: 01$ & 68.7 \\
3.85 & 60 & 0.5 & $06: 01$ & $01: 01$ & 69.4 \\
\hline
\end{tabular}

\subsection{Properties of Biodiesel Produced}

The fuel properties were found using standard methods as stated in chapter three. Table 7 presents the comparative properties of the produced biodiesel with those of the ASTM standard and petrodiesel. The properties were found to be reasonably within the ASTM standard for biodiesel. The density of the fuel produced was $874 \mathrm{Kg} / \mathrm{m}^{3}$, which is within the ASTM range. The viscosities of the biodiesel produced at the optimums ware found to be within the ASTM standard of $1.6-6.0 \mathrm{~mm}^{2} / \mathrm{sec}$. Although the ASTM does not have limitation on the calorific value, saponification value and iodine value of the biodiesel, these properties of the biodiesel produced at the optimums was found to be close to those found in the literature [8]. The energy content however was found to be $4.36 \%$ less than that of petrodiesel. The cetane number, acid number and water content of the biodiesel were all found to be within the ASTM standard. The result of the GC-MS analysis of the produced FAME at the optimum conditions confirmed the formation of FAME.

Table 7: Comparative Properties of biodiesel produced with ASTM biodiesel and Petrodiesel

\begin{tabular}{|c|c|c|c|c|}
\hline S/No & Property & FAME & ASTMD 6751-02 $2^{[16]}$ & Petrodiesel $^{[8]}$ \\
\hline 1 & Cetane Number & 51.44 & $47 \mathrm{~min}$ & 46 \\
\hline 2 & Acid Number, mg KOH/g & 0.76 & $0.8 \max$ & 0.35 \\
\hline 3 & Total glycerol, $\% \mathrm{w} / \mathrm{w}$ & 0 & 0.24 & Nil \\
\hline 4 & Water content, $\% \mathrm{v} / \mathrm{v}$ & 0 & 0.05 & 0.02 \\
\hline 5 & Density, $\mathrm{Kg} / \mathrm{m}^{3}$ & 878 & $875-900$ & 850 \\
\hline 6 & Calorific value, $\mathrm{MJ} / \mathrm{Kg}$ & 40.17 & & 42 \\
\hline 7 & Viscosity@40 C, mm²/sec & 4.8 & $1.9-6.0$ & 2.6 \\
\hline 8 & Sap. value, $\mathrm{mg} \mathrm{KOH} / \mathrm{g}$ oil & 199.7 & & Nil \\
\hline 9 & Iodine value, $\mathrm{g} / 100 \mathrm{~g}$ oil & 103.5 & & Nil \\
\hline
\end{tabular}

\section{Conclusions}

The following conclusions were drawn from this research work:

1. Significant reduction in time of transesterification reaction can be achieve by introducing the cosolvent (cyclohexane)

2. No much appreciable reduction in material consumption (Methanol/oil molar ratio) was observed

3. Transesterification proceeds to completion at an even lower impeller stirring speed of 100rpm as compared to $600 \mathrm{rpm}$ reported for conventional transesterification thereby leading to reduction in energy consumption

4. The ANOVA indicated that the models developed and its entire selected main and the interaction effects were statistically significant. The predicted $\mathrm{R}$-Squared was in reasonable agreement with the adj R-Squared.

5. Methanol/oil molar ratio was found to be the most significant factor affecting cosolvent transesterification, followed by catalyst 
concentration, then temperature and time. However, methanol/cosolvent volume ratio was found to be an insignificant factor.

6. The biodiesel produced was found to have properties that are within the ASTM D 6751-02 standard for biodiesel.

\section{Acknowledgement}

The financial support of the Center for Renewable Energy Research (CeRER), Umaru Musa Yar'adau University, Katsina-Nigeria is acknowledged. Also the Technical supports of the staff of the Department of Chemical Engineering ABU, Zaria and National Research Institute of Chemical Technology, Zaria are also acknowledged.

\section{References}

[1] Demirbas, A. (2009). Progress and Recent Trends in Biodiesel Fuels. Elsevier journal of energy conversion and management (50) Pp. 14-34.

[2] Alptekin, E., Canakci, M., (2008). Characterization of the Key Fuel Properties of Methyl Ester-Diesels. Journal of Fuel 88(1) Pp. 75-80.

[3] Vicente, G., Martinez, M., Aracil, J. and Esteban, A., (2005). Kinetics of Sunflower Oil Methanolysis. Industrial and Engineering Chemistry Research 44 (15) Pp 5447-5454.

[4] Antolin, G., Tinaut, F. V., Briceno, Y., Castano, V., Perez, C., Ramirez, A. I., (2002). Optimization of Biodiesel Production by Sunflower oil Estrification. Journal of Bioresource Techenology 83 (2) Pp. 111-114.

[5] Van Gerpen, J. (2005). Biodiesel Processing and Production, Journal of Fuel Processing Technology. (86) Pp. 1097 1107.

[6] Caglar, E. (2007). Biodiesel Production Using Co-solvent.
European Congress of Chemical Engineering (ECCE-6), Copenhagen 16-20 September 2007, Izmir Institute of technology.

[7] Whitcob .P, Oehlert G. (2000) Design Expert Software Version 6.0 User's Guide.Stat Ease Inc.

[8] Singh, R. K. \& Padhi, S. K., (2009). Characterization of Jatropha Oil for the Preparation of Biodiesel. Natural Product Radience.

[9] Refaat, A. A. (2010). Different Technique for the Production of Biodiesel from Waste Vegetable Oil. International Journal of Environment, Science and Technology 7 (1) Pp. 183-213.

[10] Mohammed-Dabo, I.A., Ahmad, M.S., Hamza, A., Muazu, K. and Aliyu, A. (2012): Co-Solvent Tranesterification of Jatropha Curcas Oil to Biodiesel. Journal of Petroleum Technology and Alternative Fuels (JPTAF) 3(3): 1-11. Available at http://www.academicjournals.org/JPTAF

[11] Makkar, H.P.S, Aderibigbe, A.O. and Becker, K. (1997), Comparative Evaluation of Non-toxic Varieties of Jatropha Curcas. Journal of Food chemistry 62 (2) Pp. $202-218$.

[12] Abitogun, S. A., Omosheyin, A. C., Oloye, D. A. and Alademehin, O. J. (2009) Extraction and Characterirization of Sunflower Crude Oil. The International Journal of Nutrition and Wellness. 21(1), Pp.21-29.

[13] Freedman, B., Pryde E.H, Mounts T.L. (1982), Variables Affecting the Yields of Fatty Ester from Transesterified Vegetable Oils. Journal of American Oil Chemist Society (61) Pp.1638-1643.

[14] El Diwani, G., Attia, N. K., Hawash, S. I. (2009). Development and Evaluation of Biodiesel and By-products from Jatropha Oil. International Journal of Environment, Science and Technology 6 (2) Pp. 219-224.

[15] Van Gerpen, J. (2009). Biodiesel Production Technologies, University of Idaho Dept. of Biological and Agricultural Engineering. Pp. 885-7891.

[16] National Biodiesel Board of United State of America, 2008 